Vol. 14, No. 52, July 2019, 1191-1200

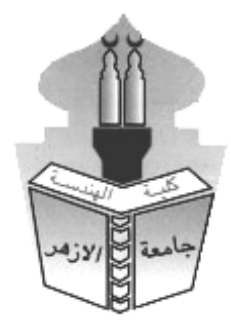

\title{
GOOD DESIGN FOR LAYOUT IS A WAY TO PROTECT MUSEUMS FROM THEFT ARCH.
}

\author{
Nashwa Mostafa Bahgat Ali \\ Technical offece manager \\ arch_nashwamostafa@yahoo.com
}

\begin{abstract}
In light of the risks and challenges faced by museums which may hinder its cultural role, must take policies and procedures which qualifies them to perform their role towards their holdings and visitors, and this is by preserve them and protection from external risk factors, and provide security and safety to the perimeter of the external building first before taking care of the museum itself, where good design of the museum's layout is the first line of defense against any infiltration and penetration. Perhaps the first challenges are security and protection is the museum's location choice, preferably away from vital installations and security of the city with the availability of a specific external road network and access routes to the museum, preferred to surround the museum by a large garden give an aesthetic appearance and used for outdoor museum display, more importantly to provide a clear view of surveillance and insurance through the void space between the layout fence and the museum itself.

The aim of the research is to monitor and study a variety of design methods for layout elements providing means of protection and insurance by reviewing some design requirements to provide.
\end{abstract}

\section{KEY WORDS : Protection of building External borders - Layout protection - Museums theft.}

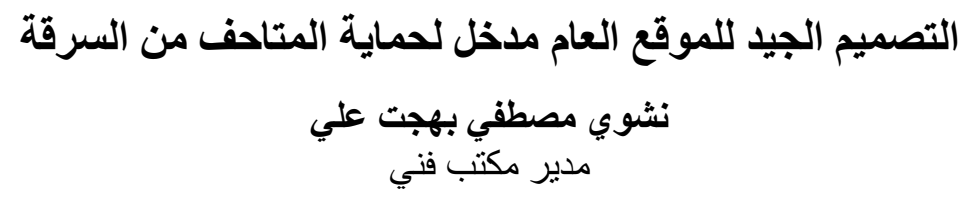

في ظلخ الأخطار : البح التحديات التي تو اجهها المتاحف و التي قد تعيق قيامها بدورها التقافي المنوط بها ، يجب أن يتخذ من

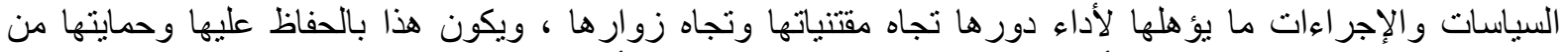

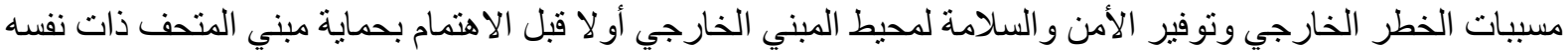

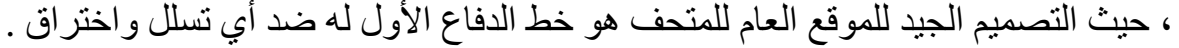

ولعل أول التحديات الخاصة بالأمن والحماية هو اختيار موقع المتحف ، يفضل أن يكون بعيدا عن المنشآت الحيوية و الأمنية للمدينة مع تو افر شبكة طرق خارجية محددة طرق الاقتر اب للمتحف ، ويفضل أن أن بحيط بالمتحف حديقة واسعة

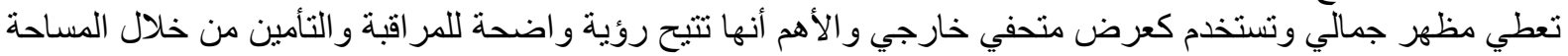

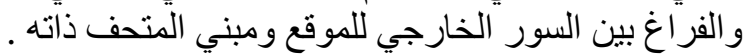

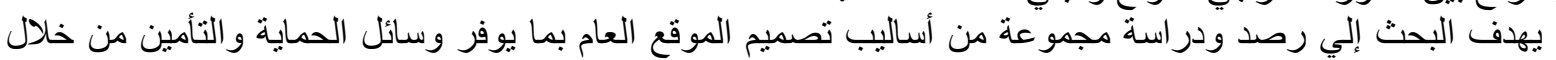

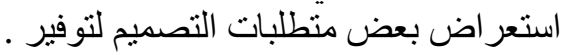

الكلمات المفتاحية : حماية المحيط الخارجي للمباني ـ تأمين الموقع العام ـ سرقة المتاحف . 
يمثل الموقع أهمية كبيرة في نجاح المتحف وتحديد نو عها وقيامه بدوره الفعال ، حيث برتبط بالخطة العامة للمتحف

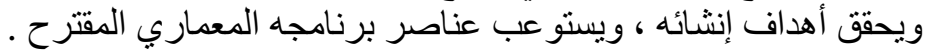

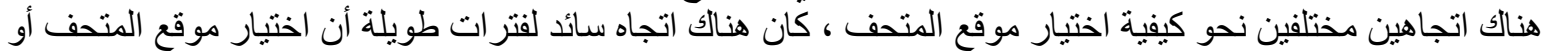

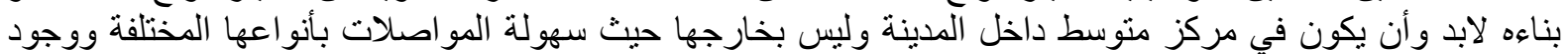

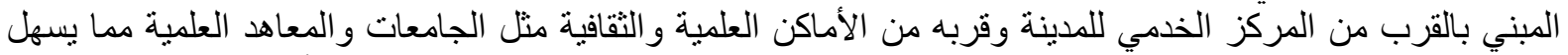

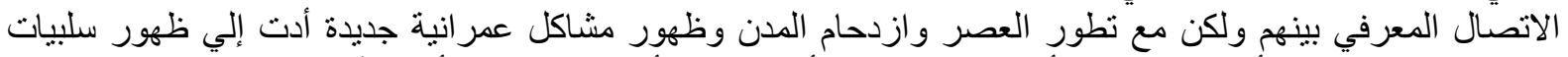

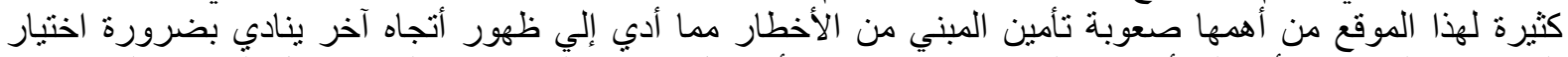

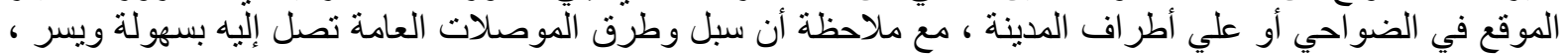

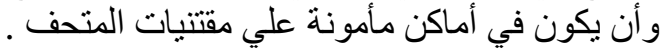

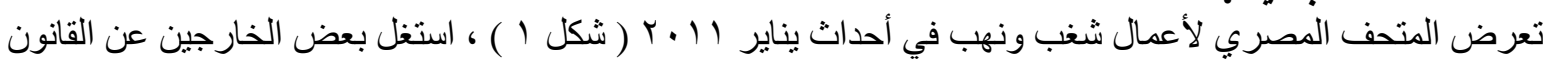

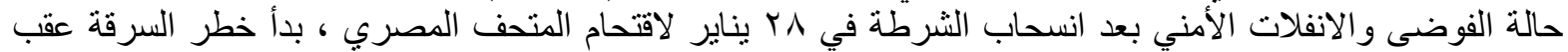

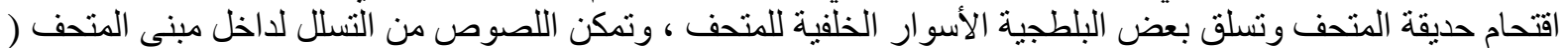

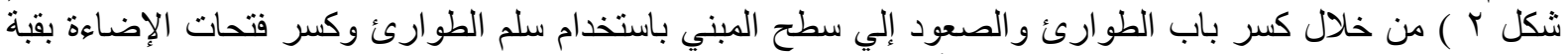

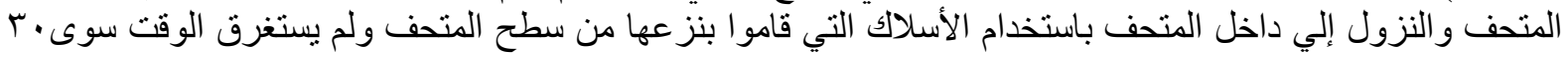

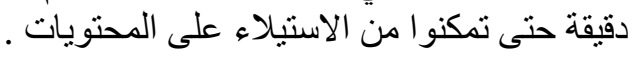
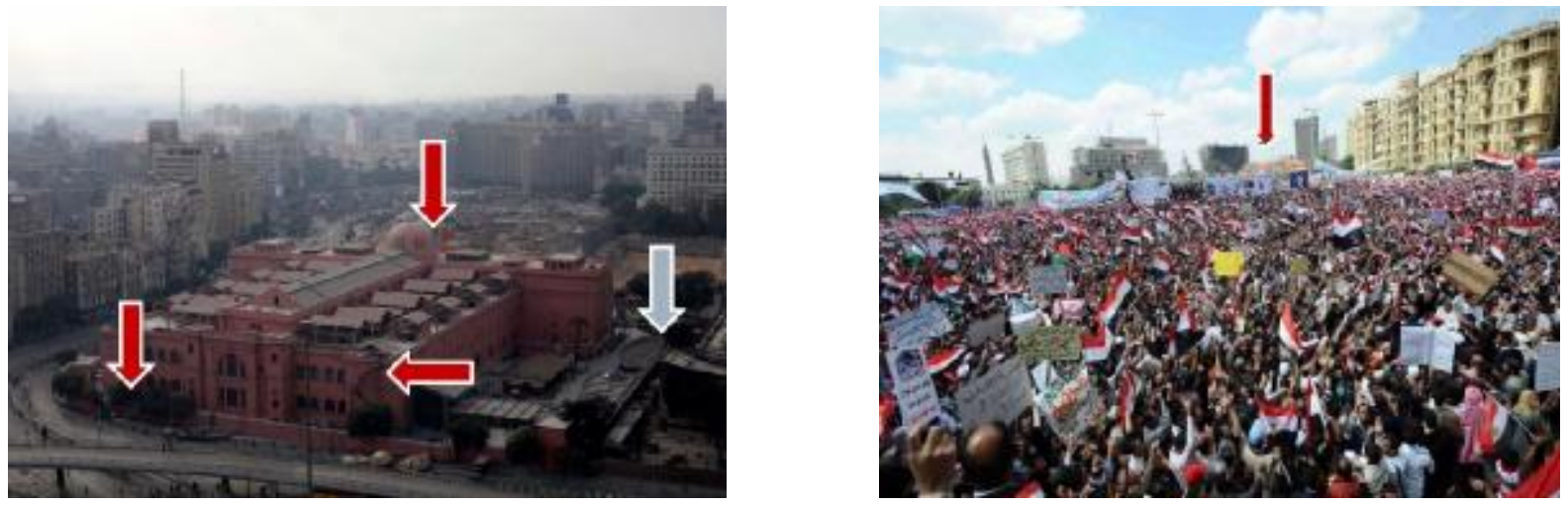

شكل ( ץ ) : لقطة خارجية توضح الأماكن التي تم التسلل

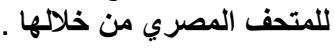

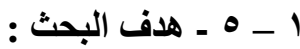

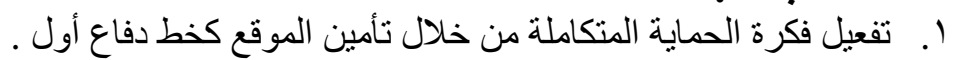

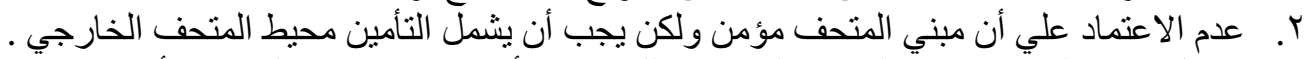

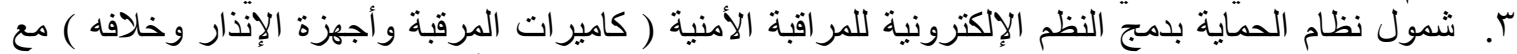

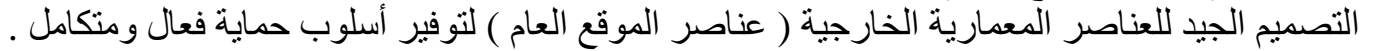

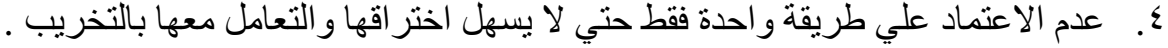

$$
\text { : } 1
$$

لتحقيق الأهداف السابقة ينتهج البحث منهجاً تحليلياً لأغلب العناصر المعمارية المنو اجدة بالموقع العام من خلال سردها

$$
\begin{aligned}
& \text { وتوضيح دور ها في الحماية و التأمين . } \\
& \text { مقسم إلي أربعة أجزاء : في الإية }
\end{aligned}
$$

الجزء الأول نظرة عاهة ألزة علي الموضو ع ومفاهيمه ويهذف للتوعية بأهميته .

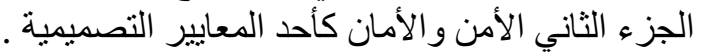

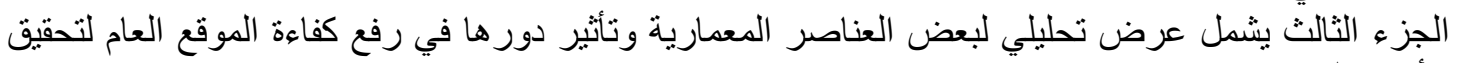
الأمن و الحماية . 


$$
\begin{aligned}
& \text { التصميم الجيد للموقع العام مدخل لحماية المتاحف من السرقة } \\
& \text { الجزء الر ابع وهو خلاصة البحث التي تشتمل علي النتائج و التوصيات . }
\end{aligned}
$$

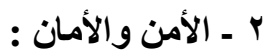

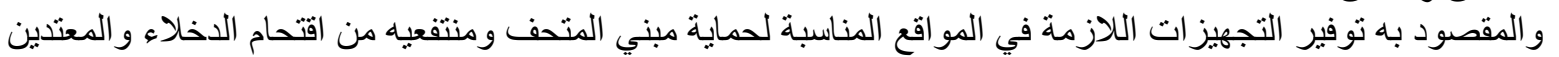

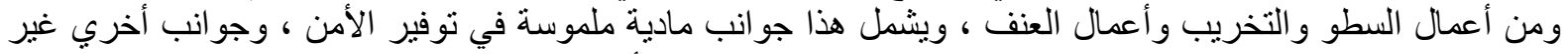

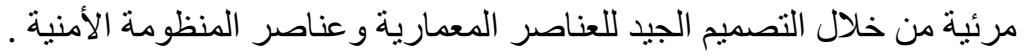

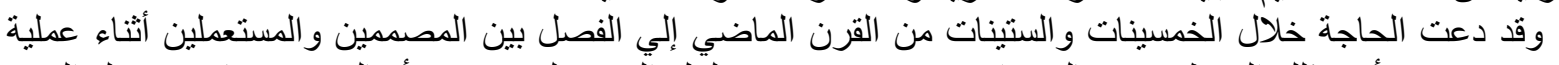

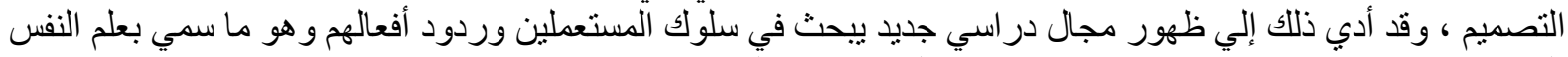

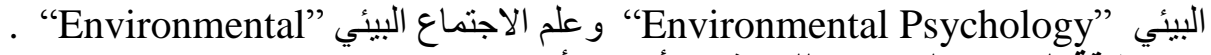

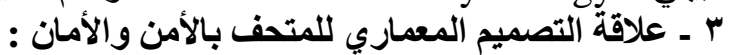

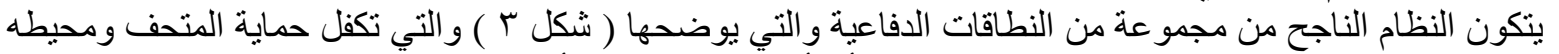

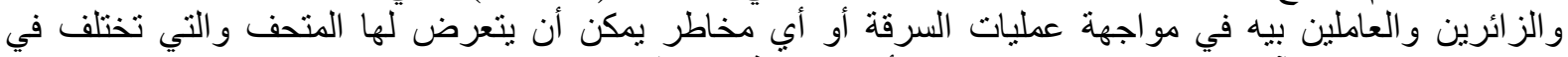

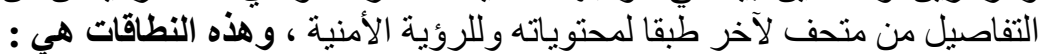

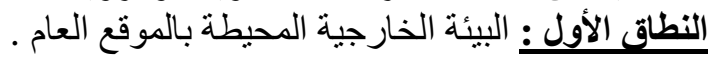

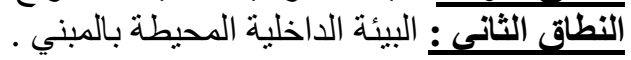

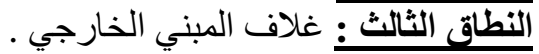

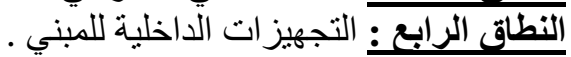

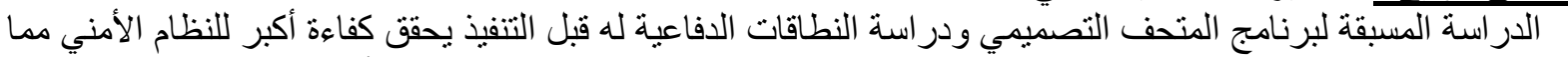

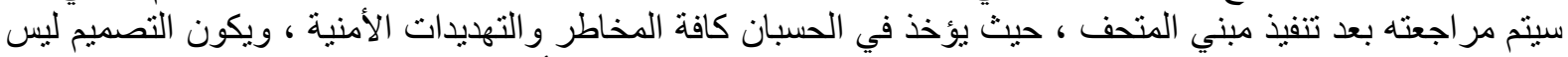

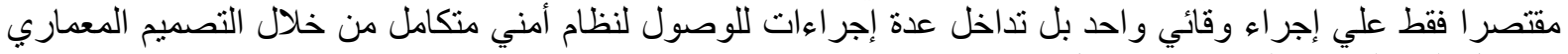
ووسائل التكنولوجيا و الحر اسات ( شكل ع ع ) .
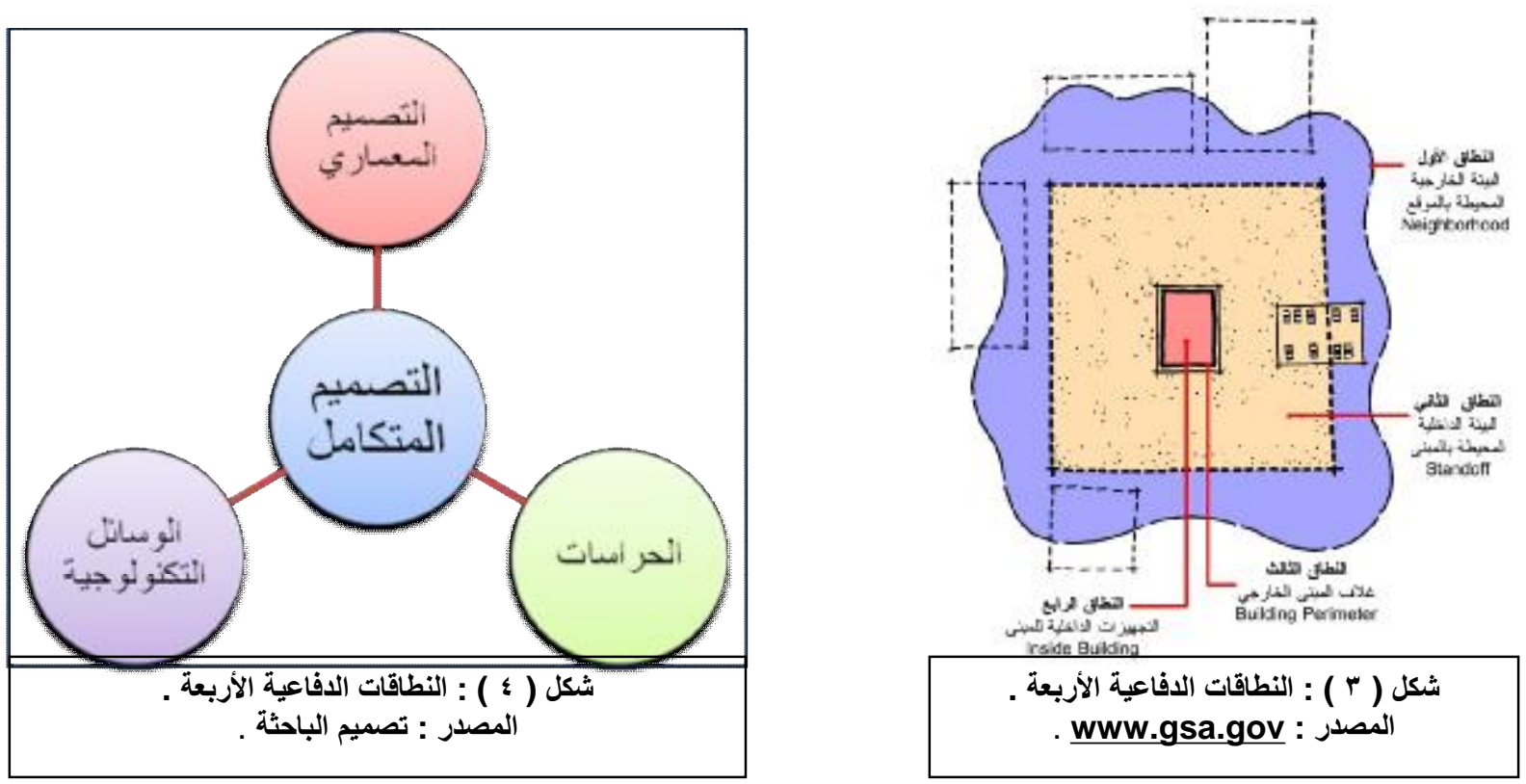

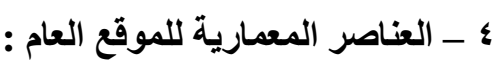

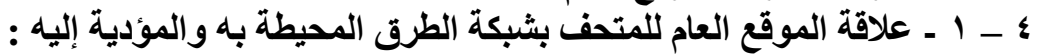

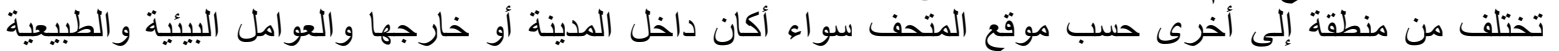

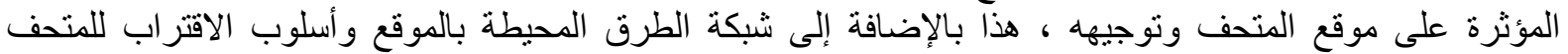

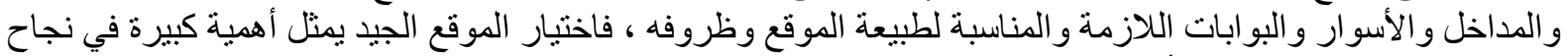
حماية المتحف وتحديد طرق وأساليب الحماية الخارجية ( شكل ه ه ، 7 ) . 

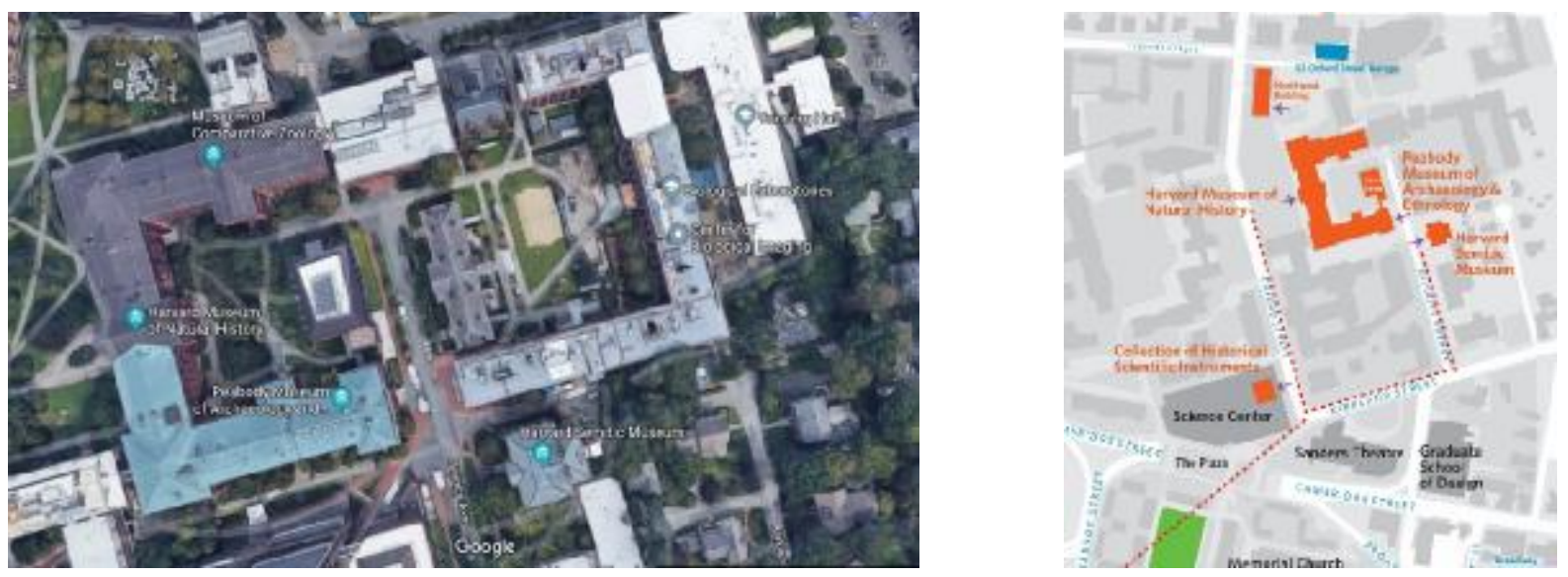

شكل ( ه ، 1 ) : يوضحان موقع متحف The Peabody Museum وعلاقته داخل المدينة وشبكة الطرق المؤدية إليه . www.peabody.harvard.edu : المصدر

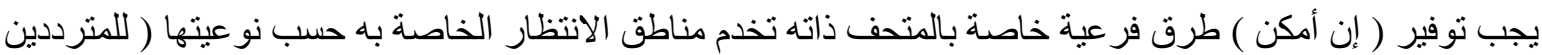

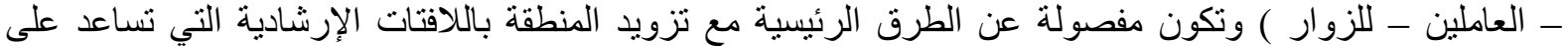

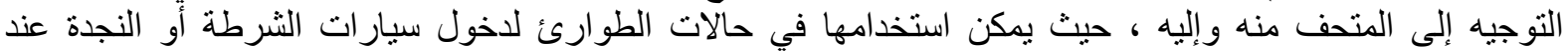

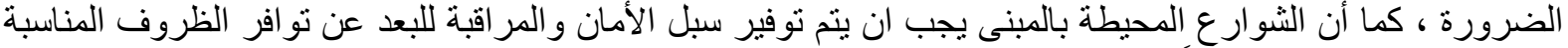

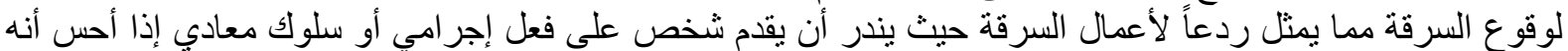

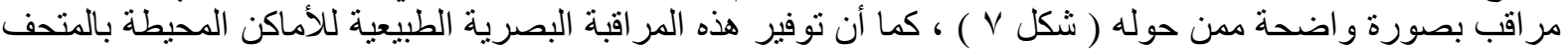

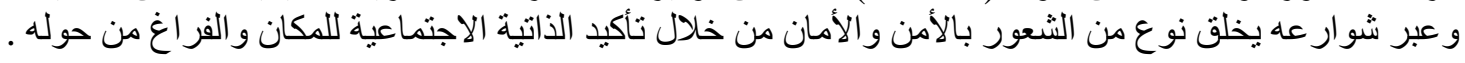

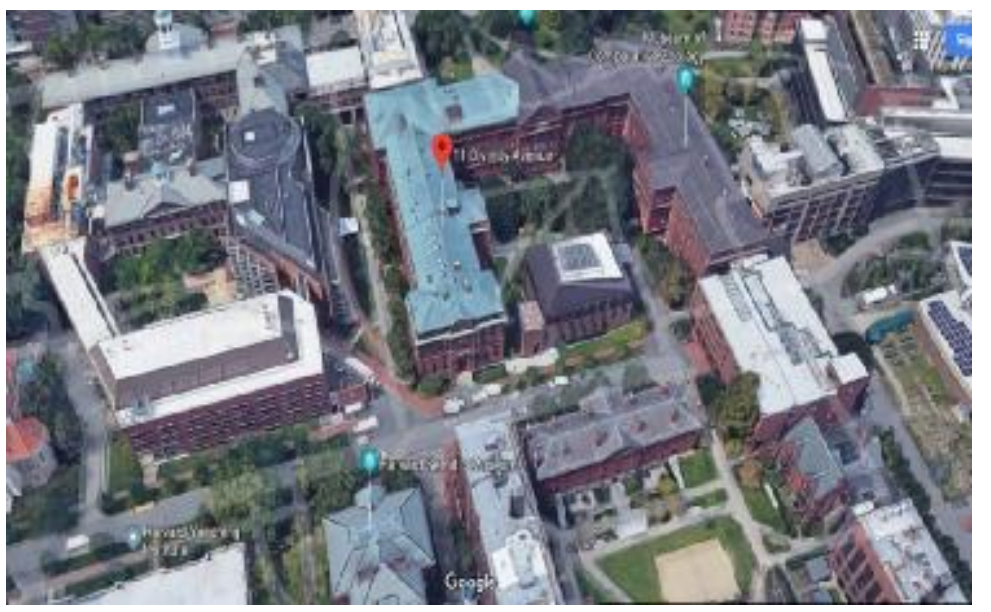

شكل ( V ) : وضوح المراقبة البصرية لموقع

متحف The Peabody Museum

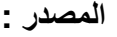
www.peabodv.harvard.edu تنبنى الأسو ار أساساً لأهداف أمنية فهي خط الدفاع الأمني الأول ومع ذللك نجد أنها

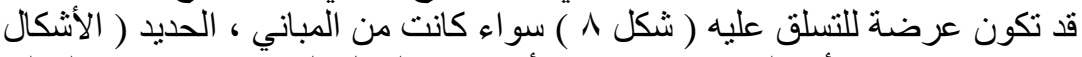

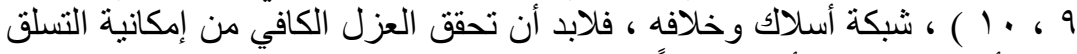

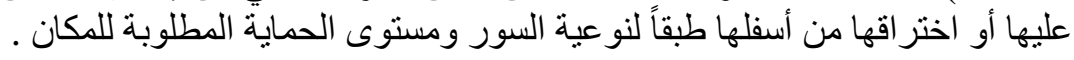

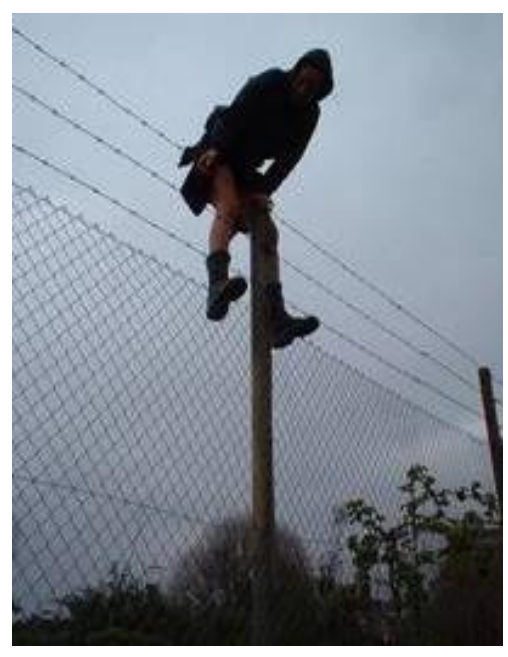

شكل ( A ) : الأسوار عرضة للتسلق مهما كانت العوائق . www.irational.org/fence/catalog.html: المصوض 

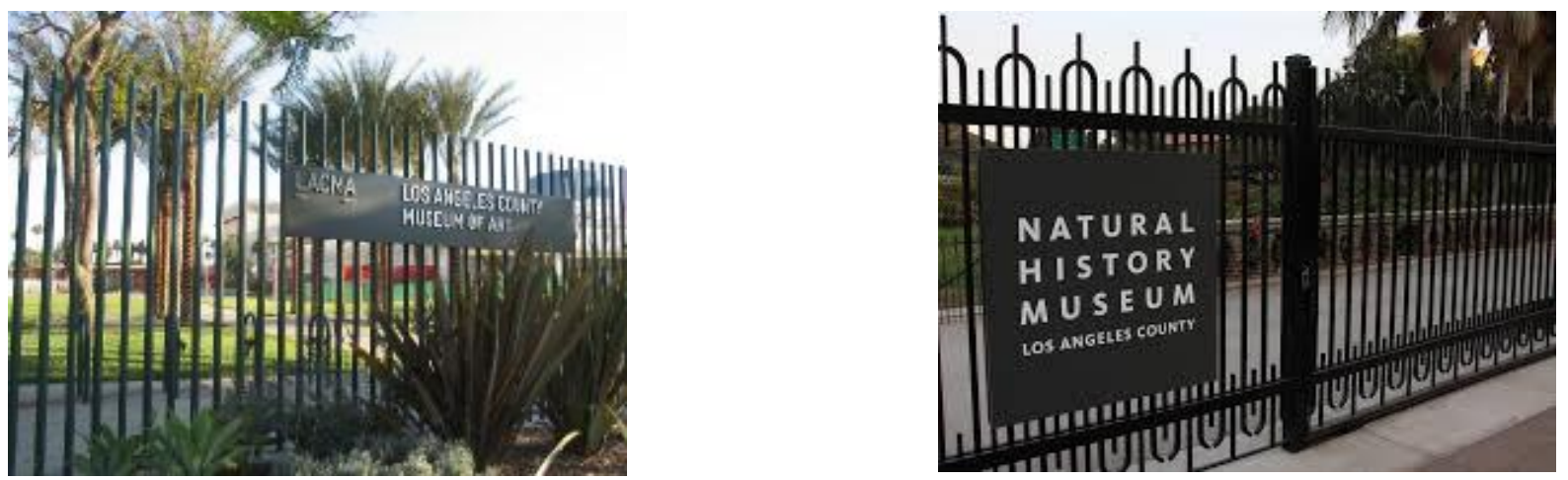

الأشكال ( 9 ، ، . 1. ) : استخدام الأسوار الحديد .

www.usglassfence.com \www.ua.all.biz/en/glass-fence: المصدر (

ولا يفضل استخدام الألو اح الزجاجية ( شكل (1 ) أو البلاستيكية ( شكل r I ) في الأسوار و التي غالباً ما تنكسر وتكون نقطة ضعف . الفطل

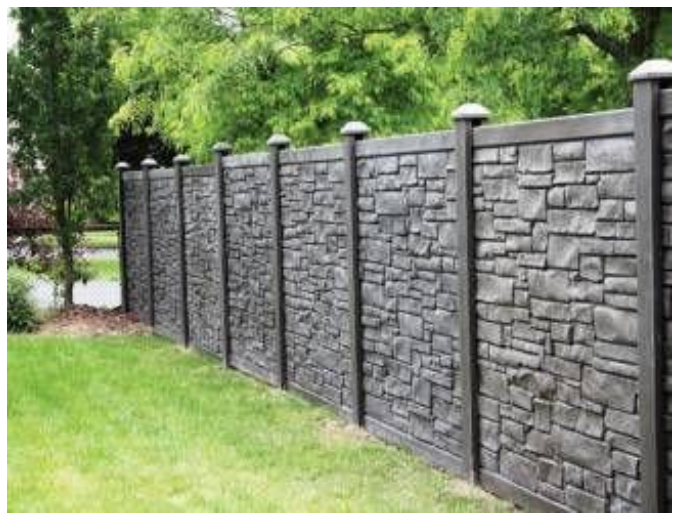

شكل ( r I ) : استخدام الأسوار البلاستيكية .

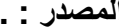

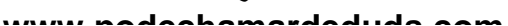

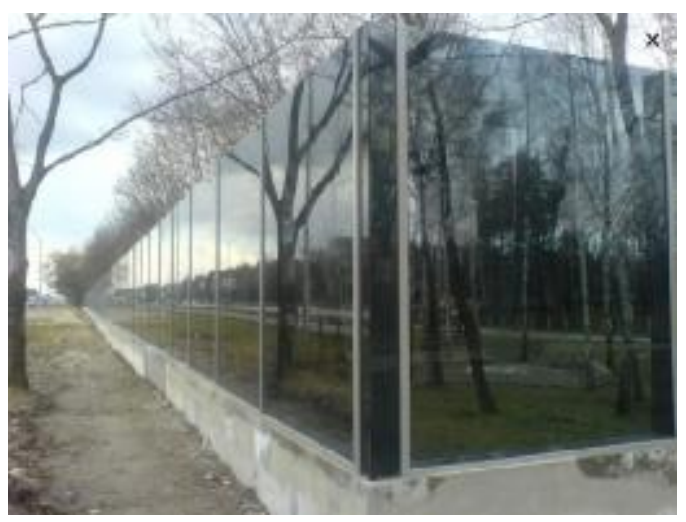

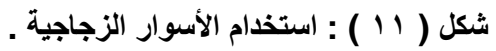
www.usglassfence.com : المصدر (1) :

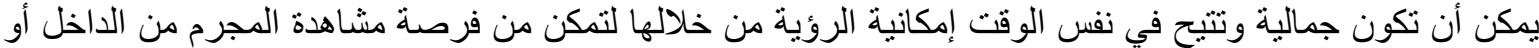

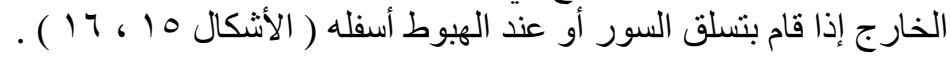

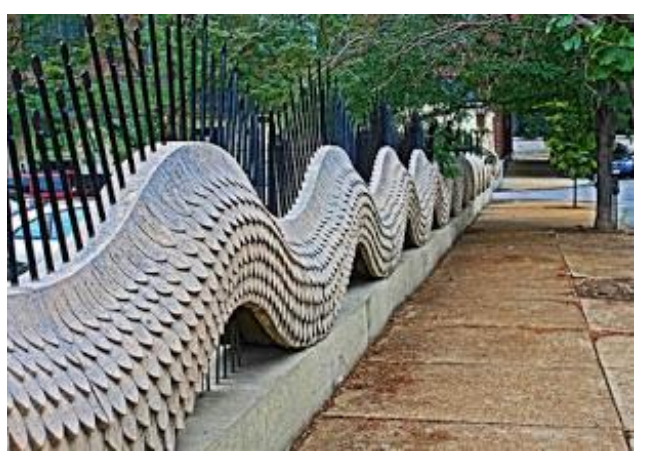

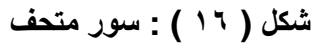

. St. LouisCity museum .www.citymuseum.org: المصدر

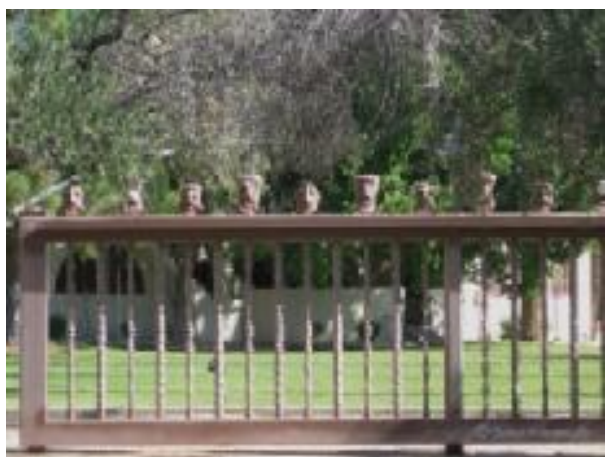

Shemer art شكل (10) : سور متحف . center and museum

www. shemerartcenter.org: المصدر

قد يتطلب الأمر عمل الأسوار مزودة بكثافات و أفر اد أمن للمر اقبة المستمرة ، مع استخدام الأنظمة الأمنية مثل كاميرات

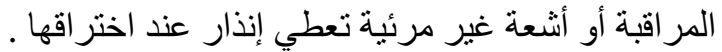



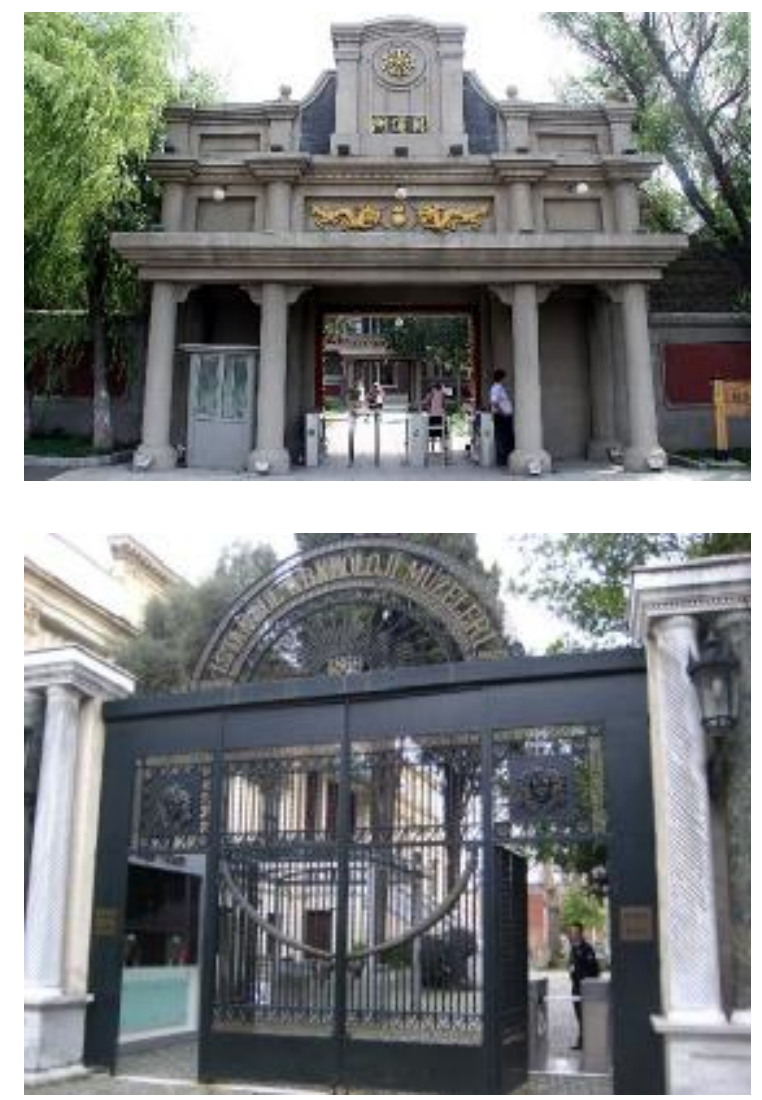

يمكن أن تكون مفصلية تحتاج إلى فراغ أكبر للحركة

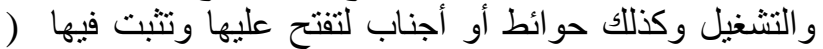

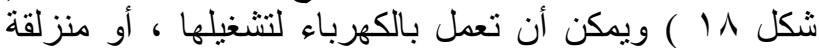

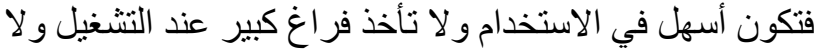

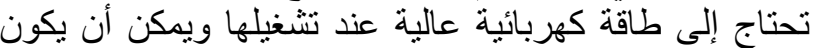

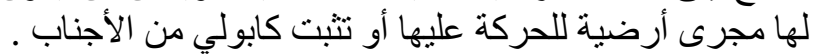

بالنسبة للأفراد بمكن التحقق من شخصيتهم بالمرور على

Istanbul Archaeology اشكل ( 11 ) : بوابات متحف Museums www.istanbulinspired.com : المصدر

غرفة الأمن الموجودة بالبو ابة و الدخول من خلالها إلى المبنى عبر بو ابات إلكترونية turnstiles ( اشكال 9 ( ، . ب ) .
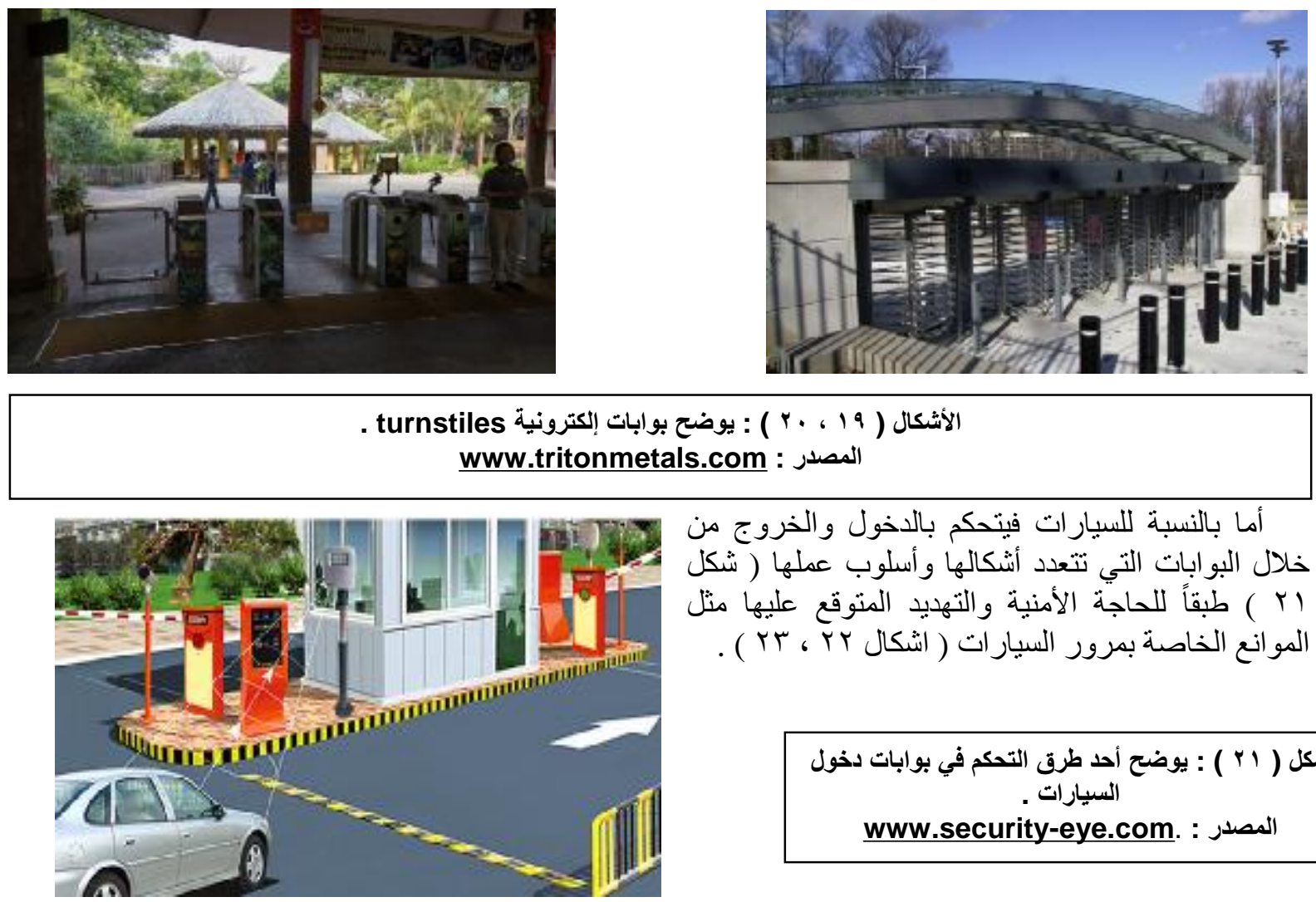

أما بالنسبة للسيارات فيتحكم بالدخول و الخروج من

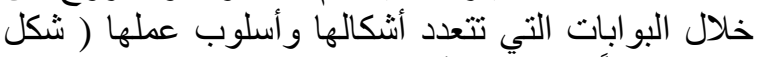

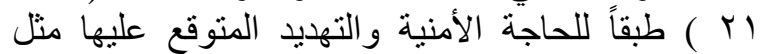

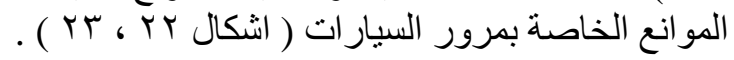

شكل ( r r ) : يوضح أحد طرق التحكم في بوابات دخول

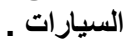

www.security-eye.com. : المصدرات 

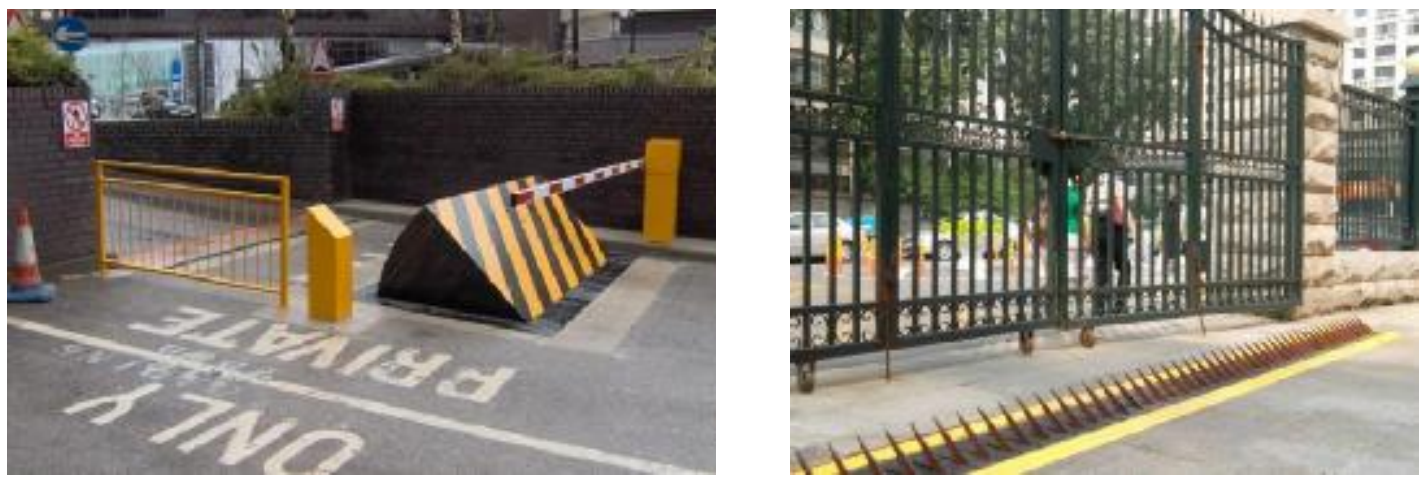

tire killer spikes \&road blocker الأشكال ( r ، ، r ) : توضح بعض أثكال موانع دخول السيارات www,hiphensolutions.com : المصدر مران

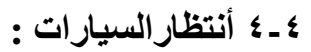
يجب أن يتوفر في أماكن انتظار السيارات درجة عالية من الأمان بأن تكون قدر الإمكان سهلة وواضحة الرؤية من

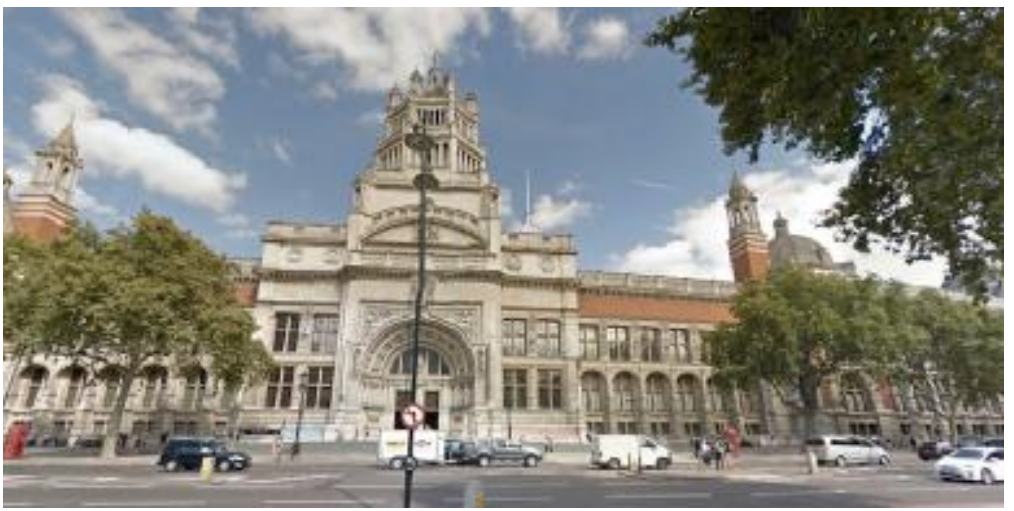

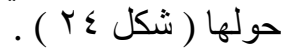

شكل ( \& r ) : توضح انتظار السيارات

The Victoria And Albert لمتحف . Museum

المصدر : www.vam.ac.uk

كما أنه يجب الفصل تماماً بين أماكن انتظار السبارات للمترددين على المبنى عن العاملين به لاختلاف فترة المكوث

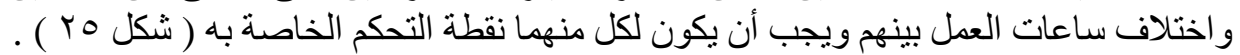

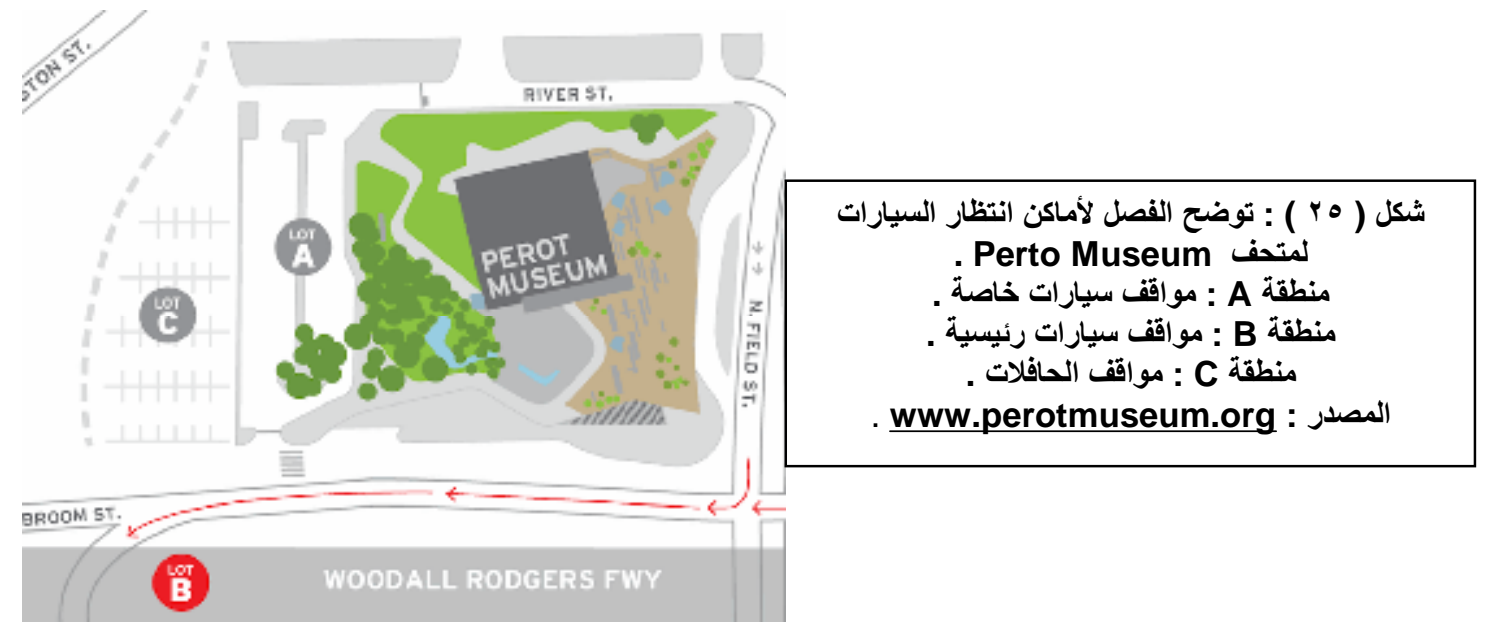

ـ ـ ـ ـ الثوارع و الممرات المحيطة بالمبنى والمؤدية إليه :

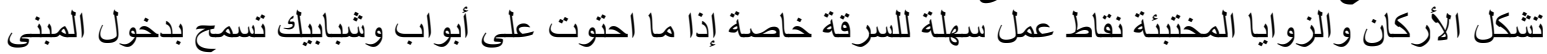

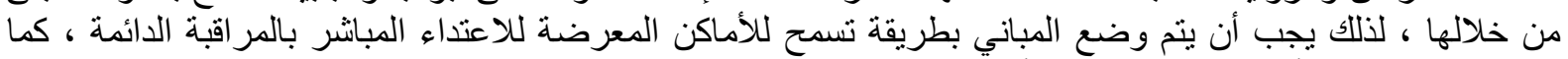

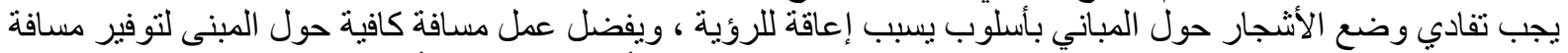

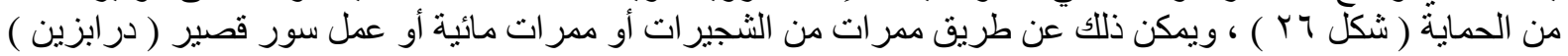


أما بالنسبة لطرق الاقتر اب من الممرات المحيطة بالمبنى و المؤدية إلى المداخل فيجب أن تكون بعيدة بالقدر الكافي بما

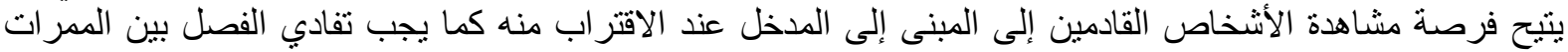

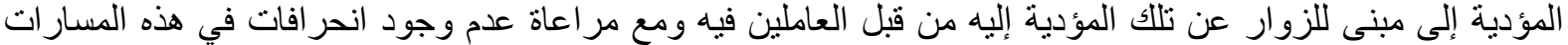

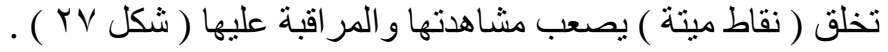
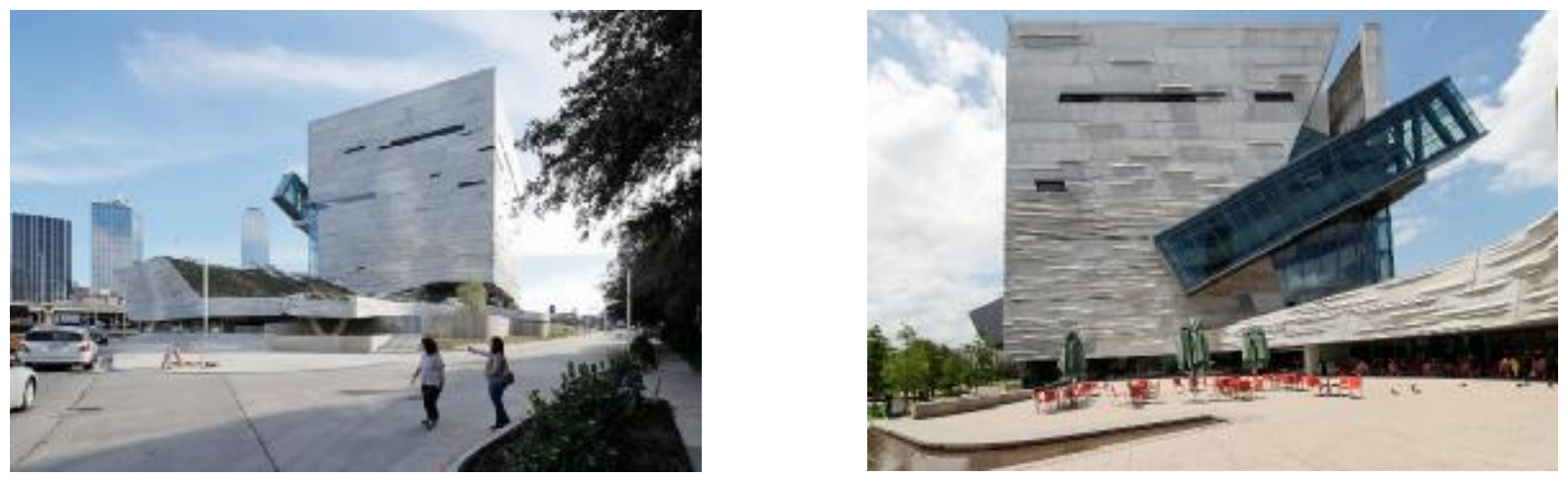

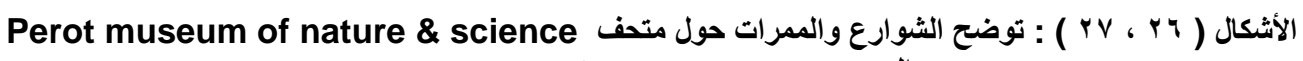
المصدر : www.perotmuseum.org

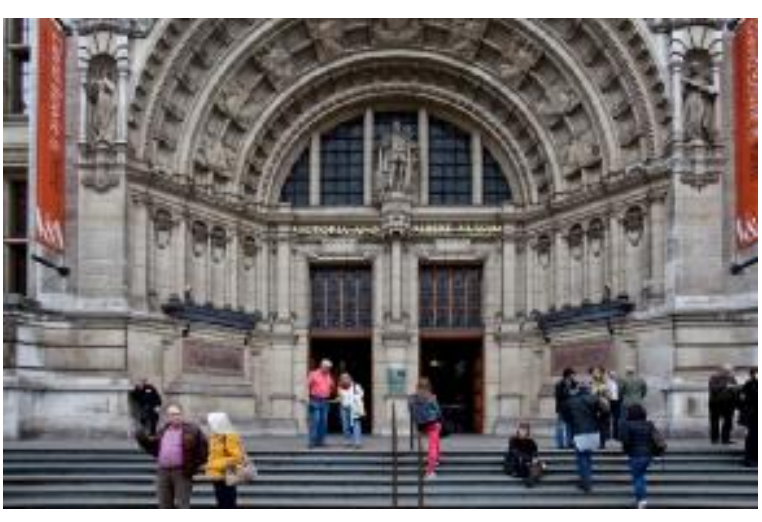

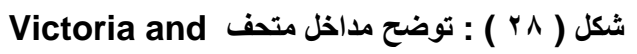
www.vam.ac.uk : المصدر albert

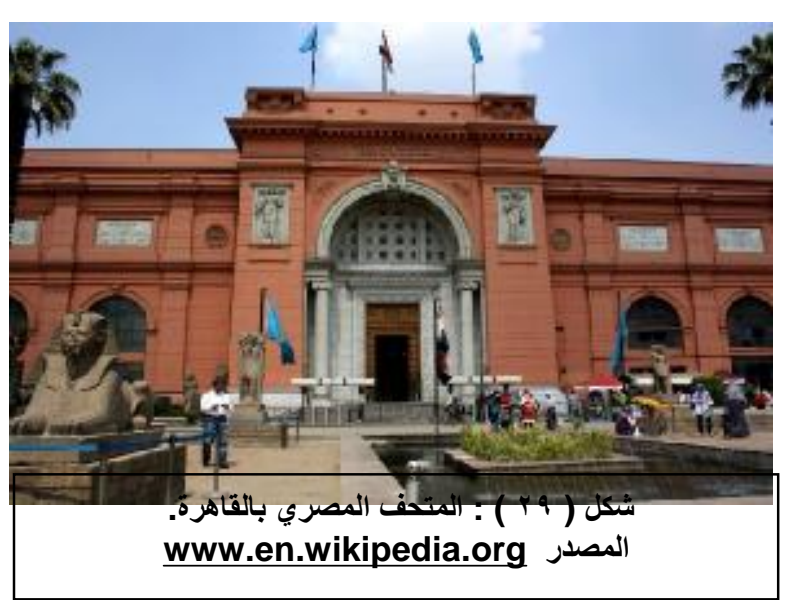

ع - 1 - ـ مداخل المبنى وطرق الاقتراب :

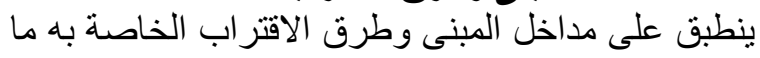

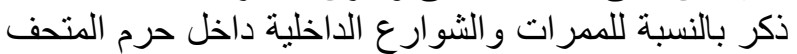

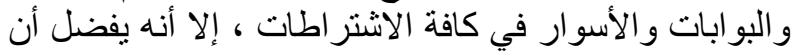

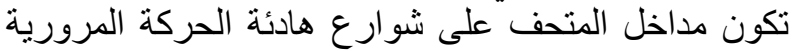

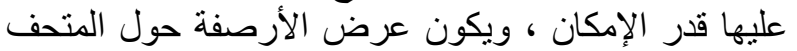

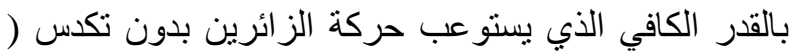

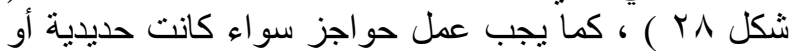
شجرية لتجنب اندفاع المنرددين على المئ المتحف وتحويل حركتهم إلى جانبي المدخل لسهولة التحكم و المر اقبة .

يجب الفصل بين مداخل المتحف لكل من العاملين فيه و المترددين عليه على أن تزود المداخل بالأبواب الحين العديدية فئية

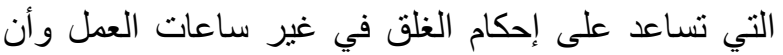

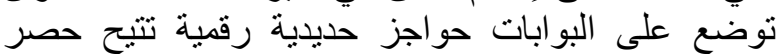

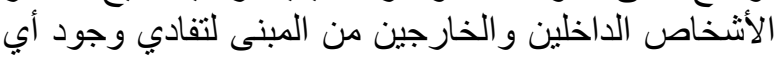

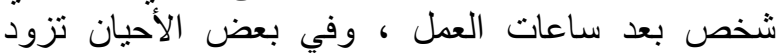

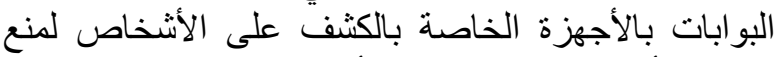

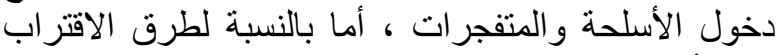

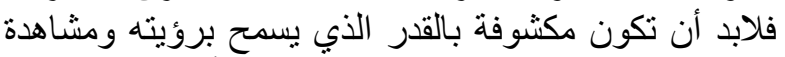

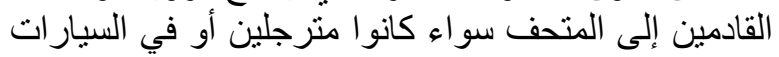

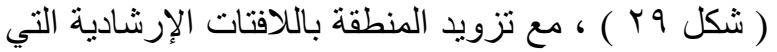

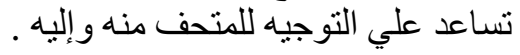




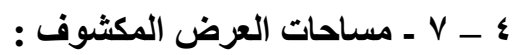

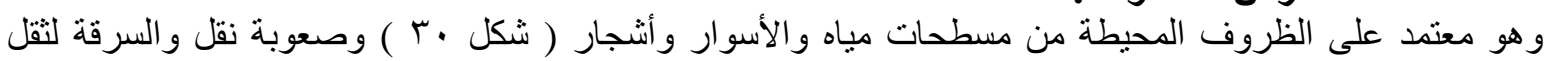

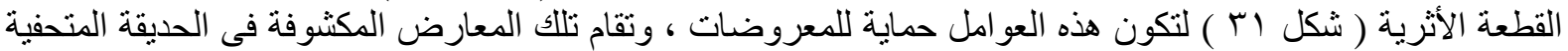

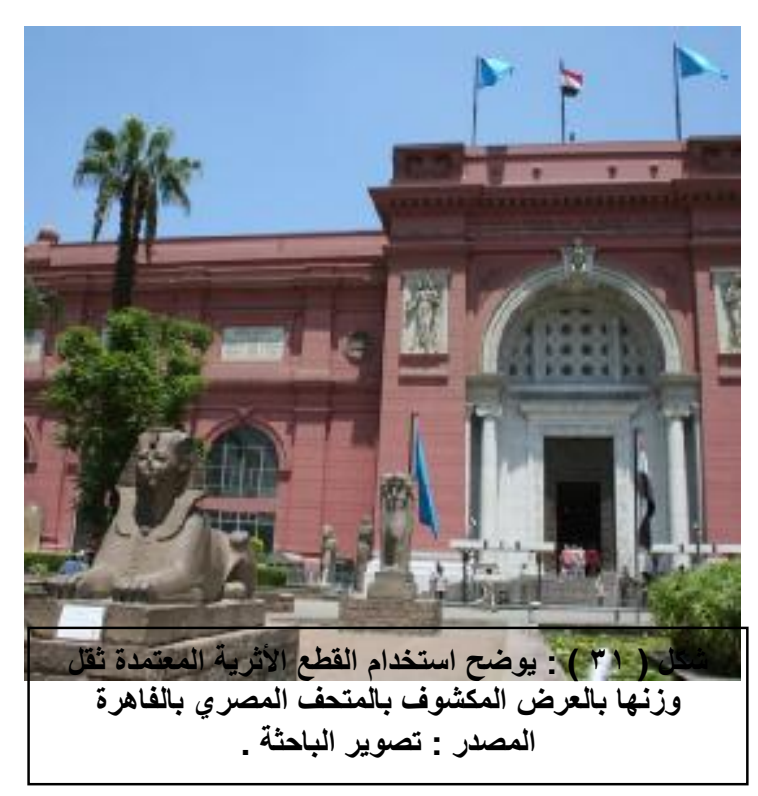

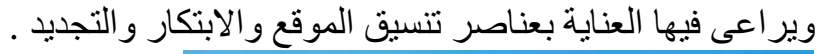

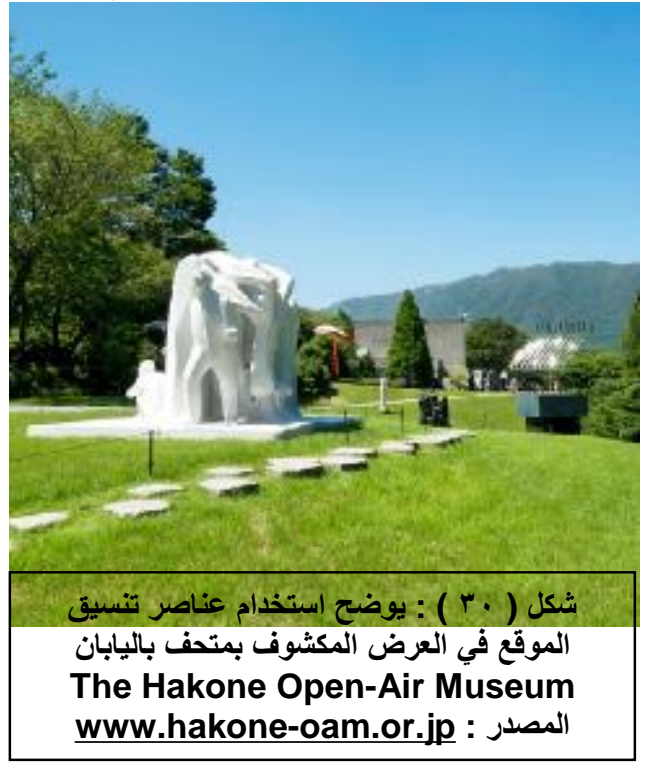

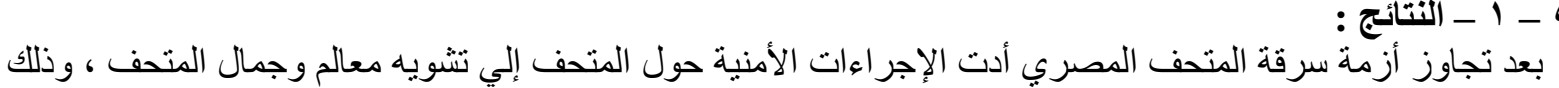

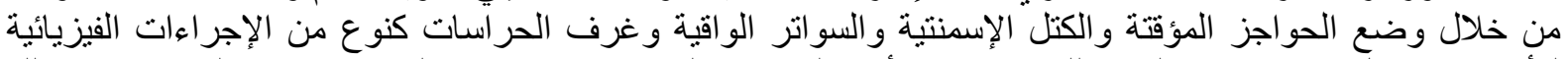

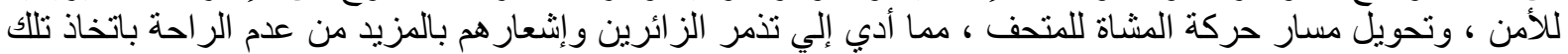

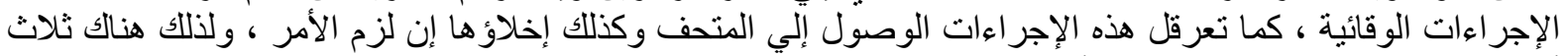

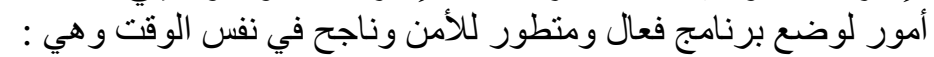

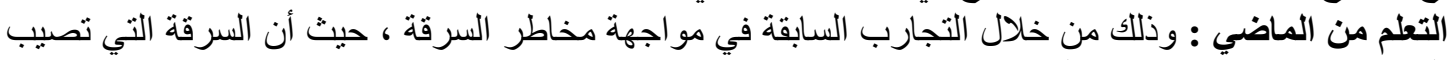

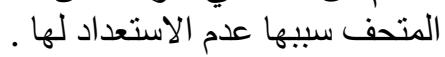

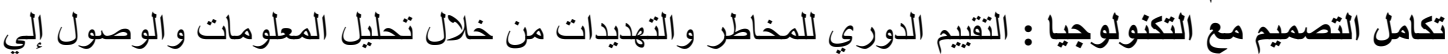

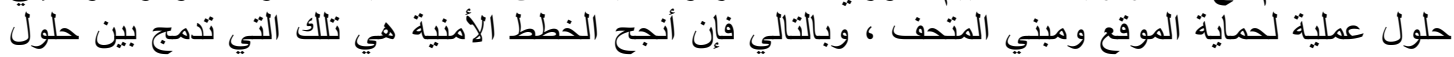

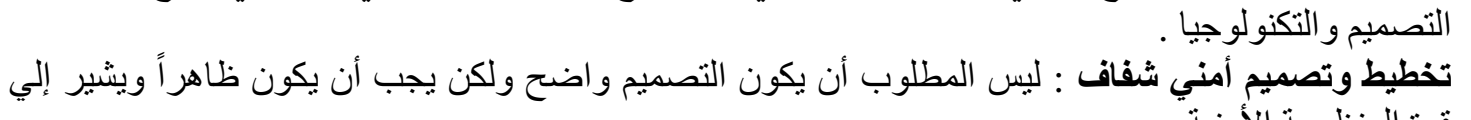

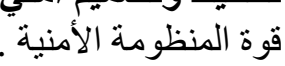

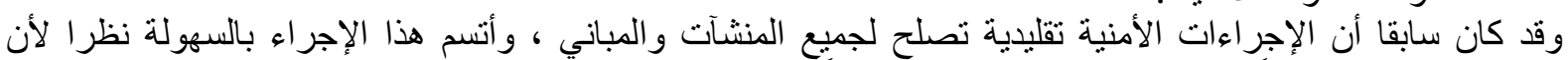

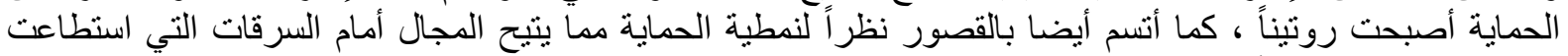
معرفة جو انب النظام الأمني وثنغر اته .

$$
\text { أولاً : ت ب - التوصيات عامة : }
$$

در اسة الموقع ومحدداته بثكل تفصيلي قبل البدء في عملية التصميم ، وضرورة سهولة وصول النجدة لموقع

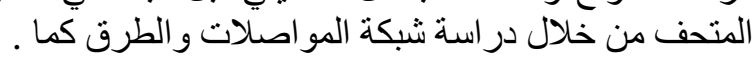

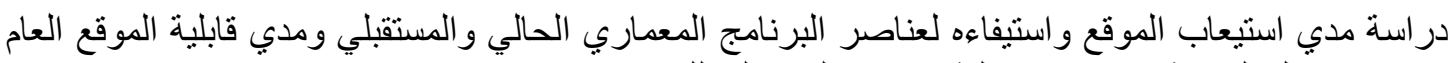

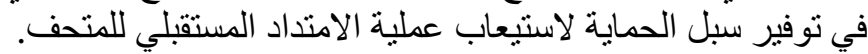

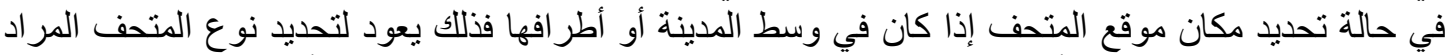

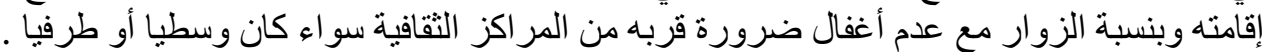

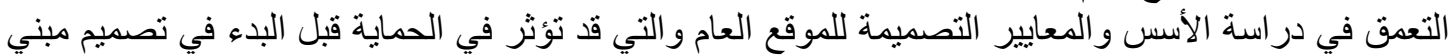
المتحف نفسـه . 


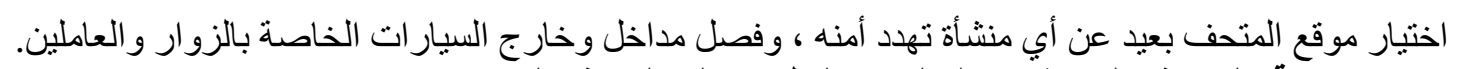

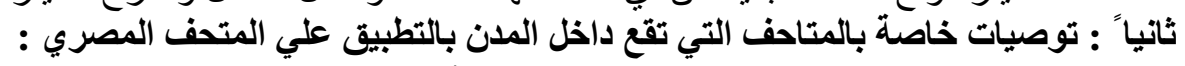

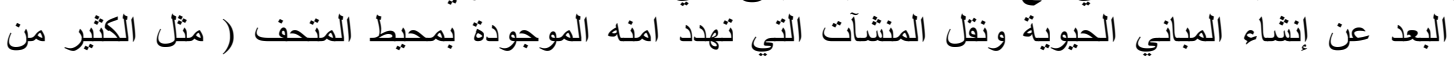

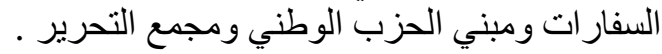

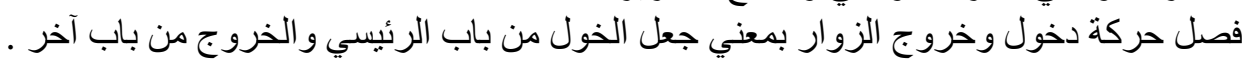

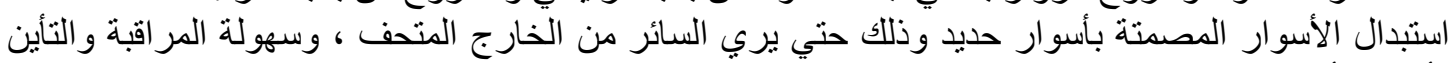

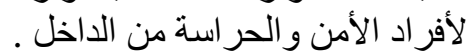

تحديث المنظومة الإلكترونية لأمن المتحف وتوسئ الألئ نطاقها ليشمل الشوارع و الميادين المحيطة ، مع ضرورة

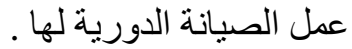
تعديل وتغيير حركة المرور بالشوار الثرا المحيطة بالمتحف من الحركة في اتجاهين إلي الحركة في اتجاه واحد فقط

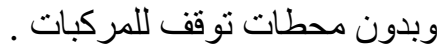
أماكن إنظظار السيار ات تكون خار المركبات النطاق المباشر للمتحف والعمل علي وجود مسافة سير مناسبة بينها وبين

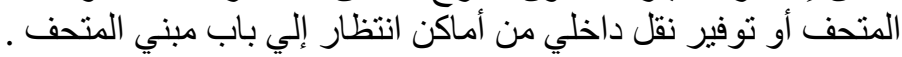

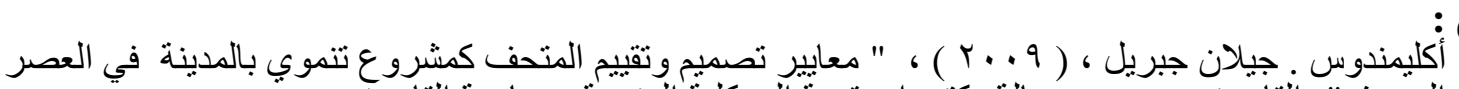

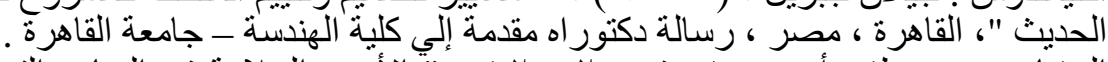

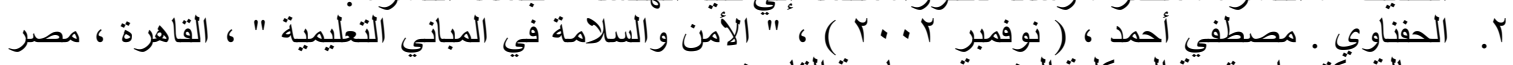

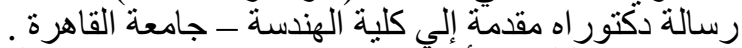

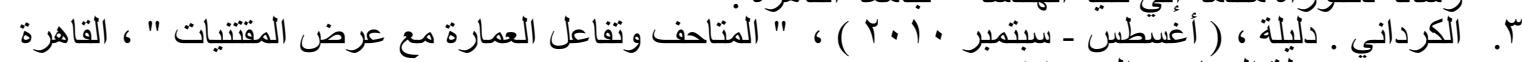

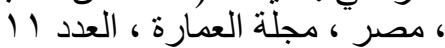

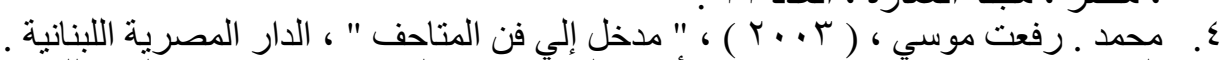

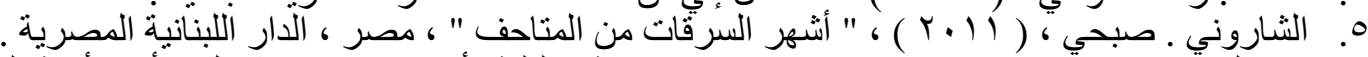

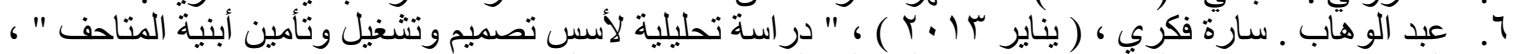

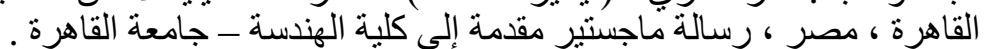

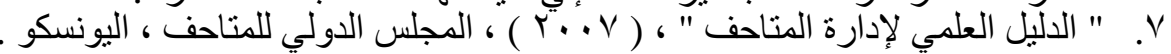

8. Bonifaci. Emily, (September 2009), "Security Scape“, U.S.A., Harvard GSD Research funded by Dumbarton Oaks Research Library/Collection .

9. Crowe.D, and Timothy, (2000), "Crime Prevention through Environmental Design “, MA and National Crime Prevention Institute, Second edition, Butterworth: Stoneham.

10. Daniel J. Benny, (2012), "Cultural Property Security: Protecting Museums, Historic Sites, Archives, and Libraries", Taylor \& Francis.

11. Paul R. Baker\& Daniel J. Benny, (15th June 2012), "The Complete Guide to Physical Security", Auerbach Publications.

12. "Beyond Concrete Barriers : Innovation in Urban Furniture and Security in Public Space", (January 2018), U.K., GCDN (Global Cultural Districts Network, An Initative of AEA Consulting).

13. "Crime Prevention and Security Management in Museums", (2015), Italy, ICOM \& De Luca Editori d'Arte .

14. "Landscape Architecture and the Site Security Process", (August 2016), U.S.A., WBDG: Whole Building Design Guide - a program of the National Institute of Building Sciences.

15. "Risk Management Series: Site and Urban Design for Security", (December 2007), U.S.A., FEMA - U.S. Department of Homeland Security \& Police Department city of New York

16. "The Site Security Design Guide", (June 2007), U.S.A., GSA : General Services Administration (public buildings service), Washington.

17. International Council of museums, www.icom.museum

18. Museum Security Network, www.museum-security.org 